\title{
The Plasma Membrane $\mathrm{H}^{+}$-ATPase from the Biotrophic Rust Fungus Uromyces fabae: Molecular Characterization of the Gene (PMA1) and Functional Expression of the Enzyme in Yeast
}

\author{
Christine Struck, Claudia Siebels, Oliver Rommel, Marcus Wernitz, and Matthias Hahn \\ Fakultät für Biologie, Universität Konstanz, D-78457 Konstanz, Germany. \\ Accepted 24 February 1998.
}

\begin{abstract}
To study the molecular basis of biotrophic nutrient uptake by plant parasitic rust fungi, the gene (Uf-PMAI) encoding the plasma membrane $\mathrm{H}^{+}$-ATPase from Uromyces fabae was isolated. Uf-PMAI exists probably as a single gene. However, two nearly identical sequences were identified; the similarity apparently is due to two $U f$-PMAI alleles in the dikaryotic hyphae. Multiple $U f$-PMAI transcripts were observed during early rust development, and reduced amounts of a single $U f$-PMAI mRNA were observed in haustoria and rust-infected leaves. This is in contrast to elevated enzyme activity in haustoria compared to germinated spores (C. Struck, M. Hahn, and K. Mendgen. Fungal Genet. Biol. 20:30-35, 1996). Unexpectedly, the PMA1encoded rust protein is more similar to $\mathrm{H}^{+}$-ATPases from plants (55\% identity) than from ascomycetous fungi $(36 \%$ identity). When the rust PMAI cDNA was expressed in Saccharomyces cerevisiae, both the wild-type enzyme and a mutant derivative $(\Delta 76)$ deleted for the $76 \mathrm{C}$-terminal amino acids were able to support growth of a yeast strain lacking its own $\mathrm{H}^{+}$-ATPases. Compared to the wild-type, the $\Delta 76$ mutant enzyme displayed increased affinity to ATP, a higher vanadate sensitivity, and a more alkaline pH optimum. These results indicate that the $\mathrm{C}$ terminal region of the rust enzyme exhibits autoregulatory properties.
\end{abstract}

Additional keywords: Uromyces viciae-fabae.

The plasma membrane $\mathrm{H}^{+}$-ATPase (EC 3.6.1.35) plays a key role in transport processes in plants, fungi, and other lower eukaryotes. By generating an electrochemical gradient of protons across the plasma membrane, this enzyme provides the energy for uptake or extrusion of metabolites and ions, thereby supporting essential cellular needs for nutrition, ion homeostasis, and growth (Serrano 1989). The $\mathrm{H}^{+}$-ATPases of several fungi and plants have been studied in detail. They are integral membrane proteins of $\approx 100 \mathrm{kDa}$ that belong to the Ptype ATPases because of the occurrence of a phosphorylated enzyme intermediate during the catalytic cycle (Serrano 1989).

Corresponding author: M. Hahn; Fax: +49 7531 883035;

E-mail: matthias.hahn@uni-konstanz.de

Nucleotide and/or amino acid sequence data are to be found at EMBL as accession number AJ003067.
The activity of the plasma membrane $\mathrm{H}^{+}$-ATPase is stimulated in vivo by glucose in Saccharomyces cerevisiae (Portillo et al. 1991) and the fungal toxin fusicoccin in plants (Johansson et al. 1993). These activators seem to overcome the negative regulation exerted by the $\mathrm{C}$-terminal domain of the protein. Removal of this region by trypsin treatment or genetic engineering results in constitutively activated enzymes (Palmgren et al. 1991; Eraso and Portillo 1994).

In contrast to the extensive work done with $\mathrm{H}^{+}$-ATPases of plants and saprophytic fungi, such as yeasts, there is little knowledge about the function and regulation of $\mathrm{H}^{+}$-ATPases from plant pathogenic fungi. In biotrophic plant-microbe interactions involving haustoria-forming rust and powdery mildew fungi, the activities of plasma membrane $\mathrm{H}^{+}$-ATPases at the interface between fungal haustoria and infected host cells have been investigated by cytochemistry in combination with electron microscopy (Spencer-Phillips and Gay 1981; Baka et al. 1995). In these studies, no ATPase activity was detected in the plant-derived extrahaustorial membranes, whereas inconsistent results were obtained with regard to the activities of haustorial plasma membranes. Recently, measurements with membrane proteins from isolated rust haustoria showed that the activity of the $\mathrm{H}^{+}$-ATPase is several-fold higher compared to the activity in fungal uredospores and germ tubes (Struck et al. 1996). This was taken as evidence that the fungal $\mathrm{H}^{+}$-ATPase plays an important role in nutrient uptake by rust haustoria. Further support for this idea was provided by the characterization of a putative amino acid-proton cotransporter that is specifically expressed in the plasma membrane of Uromyces fabae haustoria (Hahn et al. 1997).

With the goal of clarifying the role of the rust $\mathrm{H}^{+}$-ATPase for biotrophic nutrition, we began by cloning the corresponding gene (Uf-PMAl) from $U$. fabae. The expression of $U f$ $P M A 1$ is developmentally regulated during fungal pathogenesis. Functional expression in yeast of $U f$-PMAl and a derivative with a C-terminal deletion was achieved. Enzymatic differences between wild-type and mutant $\mathrm{H}^{+}$-ATPases indicate the $\mathrm{C}$-terminal domain plays a regulatory role.

\section{RESULTS}

Cloning and sequence analysis of the $U f$-PMAI gene.

Based on published sequences, a degenerate oligonucleotide was designed that corresponds to a highly conserved region 
(MTGDGVNDA) of fungal and plant plasma membrane $\mathrm{H}^{+}$ATPases (Serrano 1989). The oligonucleotide was coupled to alkaline phosphatase, and the conjugate was used to screen a $\lambda$ gt10 cDNA library from 18 -h-old in vitro-grown infection structures of $U$. fabae. Several hybridizing clones were isolated and, by partial sequencing, found to contain identical sequences that exhibited high similarity to plant and fungal $\mathrm{H}^{+}$-ATPases (data not shown). One of these cDNA clones, containing an insert of $3.0 \mathrm{~kb}$, was sequenced completely. Using this cDNA clone as a probe, a genomic clone with an insert of $\approx 18 \mathrm{~kb}$ was isolated from an $\lambda$ EMBL3 library of $U$. fabae. Comparison of the genomic with the cDNA sequence revealed that the latter was not complete. To isolate a fulllength cDNA, a DNA fragment covering the 5 ' region of the PMAl genomic sequence was used to screen a haustoriumspecific cDNA library (Hahn and Mendgen 1997). The largest clone isolated from this library contained a cDNA insert of 3,716 bp that was used for further analysis. From the genomic clone, 6,983 bp encompassing the cDNA were sequenced (Fig. 1). Sequence comparison of the two cDNA clones and the genomic clone revealed that they are identical, except for the introns in the genomic sequence and three nucleotide sub- stitutions (described below). The gene represented by these sequences was named $U f$-PMAl, according to similar genes from other organisms.

Uf-PMAl contains 10 introns that range in size from 57 to $118 \mathrm{bp}$, with an average of $71 \mathrm{bp}$. The first intron is located 298 bp upstream of the proposed start of translation, whereas the other introns are distributed over the coding region. To determine the copy number of PMA1, various restriction digests of total DNA from $U$. fabae were hybridized with a 2.7-kb PMAl cDNA probe. In most cases, the hybridizing bands were identical to those expected from the PMAI genomic sequence, except for the appearance of one additional hybridizing band in some of the digests (data not shown). Therefore, we concluded that $U f-P M A I$ exists as a single-copy gene.

The haustorial cDNA clone consists of a 386-bp 5'-terminal sequence (including a short open reading frame (ORF) between positions 91 and 105), followed by a large ORF of 2,886 and 445 bp of $3^{\prime}$-terminal sequence, without the poly(A) tail. The ATG at position 387 is probably the translational start codon, because it is preceded by a TAA stop codon located 15 nt upstream.

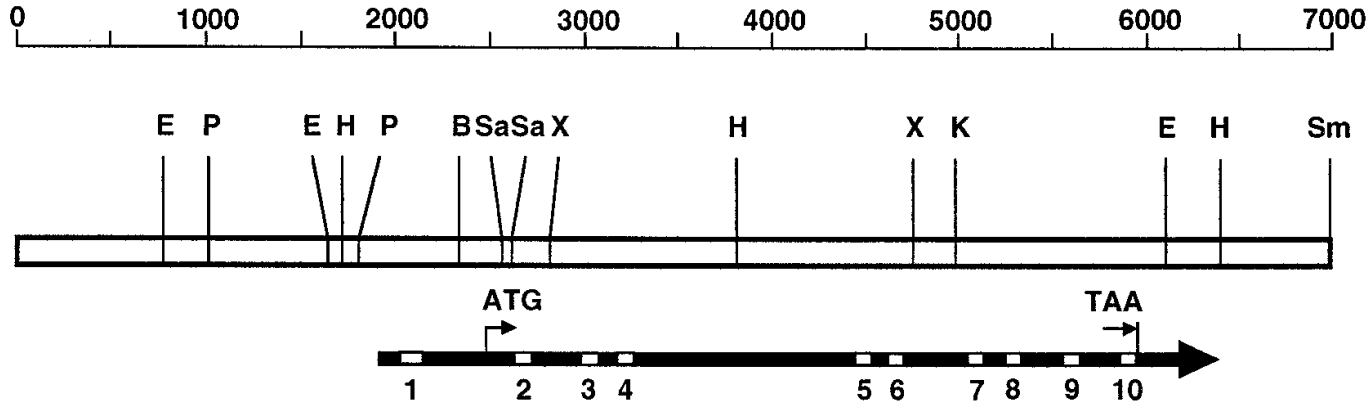

Fig. 1. Map of the Uf-PMAI gene from Uromyces fabae. The sequenced DNA is represented as a bar. The transcribed region is indicated by the bar arrow, the white boxes with numbers represent introns. The positions of start and stop codons are shown. Recognition sites for the following enzymes are indicated: BamHI (B), EcoRI (E), HindIII (H), KpnI (K), PstI (P), SalI (Sa), SmaI (Sm), and XhoI (X).

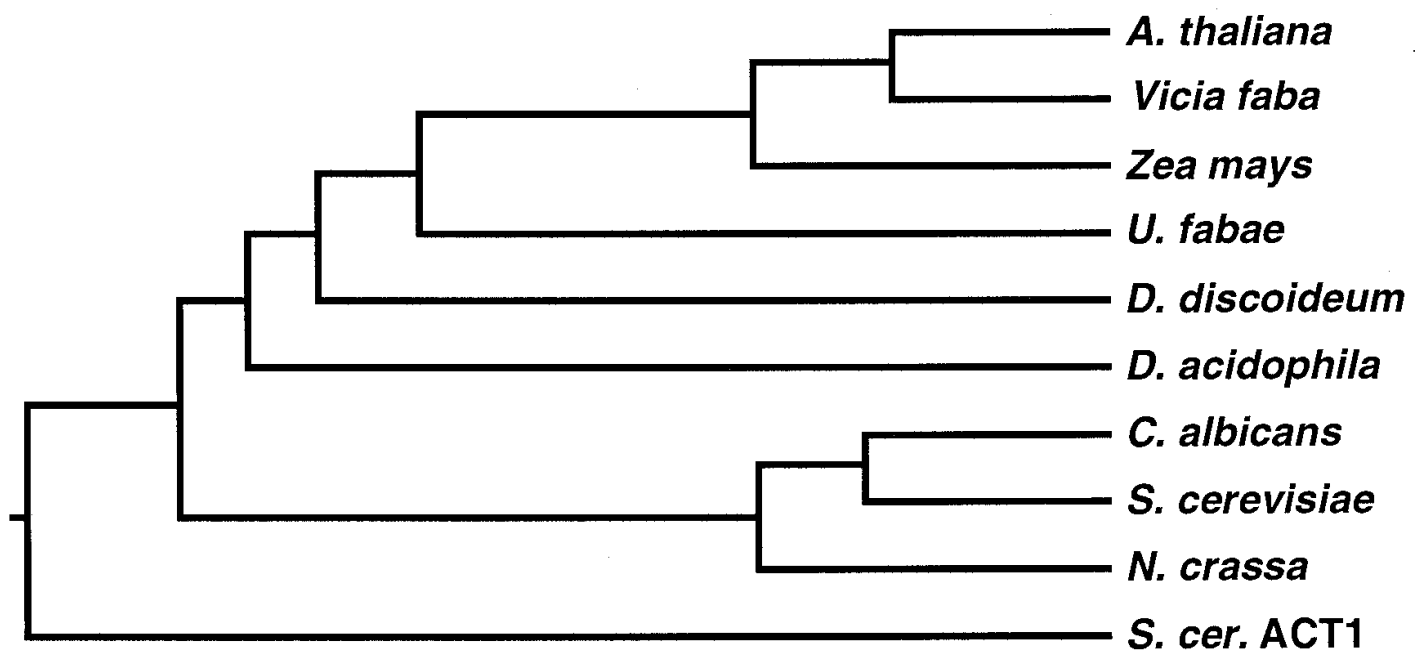

Fig. 2. Dendrogram of sequence similarities between plasma membrane $\mathrm{H}^{+}$-ATPases from various organisms. The following sequences were used for comparisons (including ACT1, a P-type $\mathrm{Ca}^{2+}$-ATPase from Saccharomyces cerevisiae, as an outgroup): Arabidopsis thaliana PMA1 (P13586); Vicia faba (S79323), Zea mays MHA1 (U09989), Uromyces fabae PMA1 (AJ003067), Dunaliella acidophila DHA1 (P54210), Dictyostelium discoideum PMA1 (P54679), S. cerevisiae PMA1 (P05030), Candida albicans PMA1 (P28877), Neurospora crassa PMA1 (P07038), and S. cerevisiae ATC1 (P05030). The clustal V method was used for multiple alignment of the amino acid sequences (Higgins and Sharp 1989). 
The ORF of the haustorial cDNA clone encodes a protein of 962 amino acids, with a predicted molecular mass of 104,915 Da. Hydropathy analysis revealed 10 highly hydrophobic stretches that probably represent transmembrane domains, according to an analysis performed with the TMpred algorithm (Hofmann and Stoffel 1993). Database searches revealed extensive sequence similarities between the PMAl-encoded protein and the plasma membrane $\mathrm{H}^{+}$-ATPases from plants and fungi and, to a lesser extent, other P-type ATPases from eukaryotes and bacteria. Pairwise alignments with the BESTFIT program (Genetics Computer Group, Madison, WI) revealed the highest scores of similarity to the $\mathrm{H}^{+}$-ATPases of plants $(\approx 55 \%$ identity), followed by the slime mold Dictyostelium, the alga Dunaliella (both 43\%), and several members of the ascomycetes (35.5 to $36.5 \%$; Fig. 2). This was unexpected because basidiomycete $U$. fabae is taxonomically significantly more closely related to the ascomycetes than to the other species listed in Figure 2.

\section{Identification of two putatively allelic PMA1 copies in the rust dikaryon.}

Three nucleotide differences were detected in the sequences of the genomic PMAl clone and the cDNA clones of both infection structures and haustoria (Fig. 3). The differences were found in the coding region; each was a silent substitution at the wobble position of the respective codons. To check whether these differences were due to cloning artifacts, the corresponding sequences of PMAl were amplified by polymerase chain reaction (PCR) from total DNA of $U$. fabae and reverse-transcription PCR (RT-PCR) from mRNA obtained from infection structures and haustoria. Direct sequencing of the PCR products revealed mixed sequences at the variable positions, with double bands of similar intensity. This indicated the presence of two nearly identical PMAl sequences in a 1:1 ratio, both in the rust genome and the mRNA of infection structures and haustoria (Fig. 3). To verify this, the amplification products obtained from the genomic DNA were cloned into a plasmid vector. Clones of individual transformants showed in six cases sequence I and in four cases sequence II. These data confirmed the presence of two nearly identical PMAl gene copies that are probably alleles in the binuclear genome of $U$. fabae race $\mathrm{I}_{2}$.

\section{Expression of $\boldsymbol{U f}$-PMAI during rust development.}

As shown previously, the activity of the rust plasma membrane ATPase is several-fold higher in haustoria than in spores of germlings (Struck et al. 1996). To analyze whether the increased enzyme activity in haustoria is due to higher transcript levels of $U f$-PMA1, Northern hybridization experiments were performed with RNA isolated from several stages of rust development, using the digoxigenin (DIG)-labeled 3.0-kb PMA1 cDNA as a probe. With several preparations of total RNA, a similar pattern of transcripts was consistently observed in early rust infection structures, whereas only a single band was observed in haustoria and infected leaves (Fig. 4A). The transcript level in haustoria (lane 6) appeared lower than those in the early growth stages (spores, germlings, and in vitro-grown infection structures) of the rust fungus. With poly(A) RNA, UF-PMA1 transcripts ranging in size from 3.5 to $4.7 \mathrm{~kb}$ could be resolved in the early rust growth stages, whereas only a single transcript of $\approx 4.3 \mathrm{~kb}$ was observed in haustoria and rust-infected leaves (Fig. 4B).

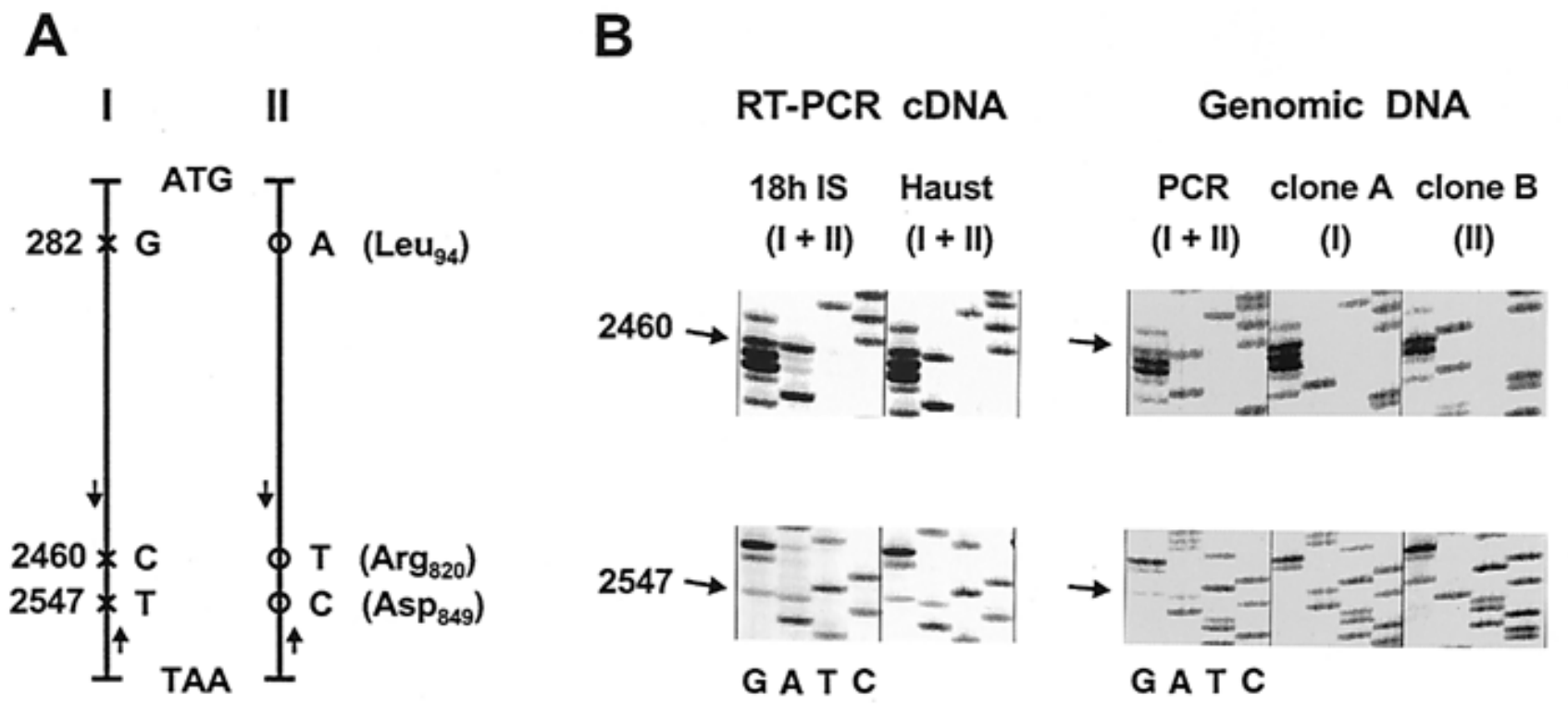

Fig. 3. Sequence dimorphism in the Uf-PMA1 gene from Uromyces fabae. A, Positions of the variable nucleotides within the coding region of the two PMAl copies. The amino acids encoded by the affected codons are shown in parentheses. The small arrows indicate the position of the primers (upstream primer: TTCTATCTTCGACCCACC; downstream primer: TTGGTTAGCGGGAATAGG) used for polymerase chain reaction (PCR) amplification of PMA1 fragments covering positions 2460 and 2547 (position 282 was not included in this analysis). B, Tracts of sequencing gels showing two dimorphic nucleotide positions (arrows). Above the sequence lanes, the PMAl copies (I and II) represented by the sequences are shown. Direct sequencing of reverse-transcription PCR (RT-PCR) amplification products was performed with cDNAs obtained from 18-h infection structures (18h IS) and haustoria (Haust) and with genomic DNA obtained from $U$. fabae uredospore germlings. Clones A and B are derived from the genomic PCR product whose sequence is shown next to them. 


\section{Functional expression of $U f$-PMA 1 and a C-terminal deletion derivative in yeast.}

The $U$. fabae PMAI cDNA and a mutant derivative $(P M A 1 \Delta 76)$ encoding a protein that lacked 76 C-terminal amino acids were cloned into the $L E U 2$ expression vector YEpPMA181. In the resulting plasmids, pUFPMA1 and pUFPMA1 $\triangle 76$, the rust cDNAs were under control of the constitutive yeast PMA1 promoter. The plasmids were transformed into yeast strain YAK2 (de Kerchove d'Exaerde et al. 1995). YAK2 is defective in both chromosomal $\mathrm{H}^{+}$-ATPase genes PMA1 and PMA2 but carries a functional yeast PMA1 gene on a plasmid (cp(GAL1)PMA1) under the control of the inducible GAL1 promoter. YAK2 strains containing pUFPMA1 or pUFPMA1 $\triangle 76$ were subjected to 5-flouroorotic acid selection to achieve loss of $\mathrm{cp}(\mathrm{GAL} 1) \mathrm{PMA} 1$. After this selection, growth of the transformed yeast strains but not of YAK2 was observed when transferred to glucose medium without leu-
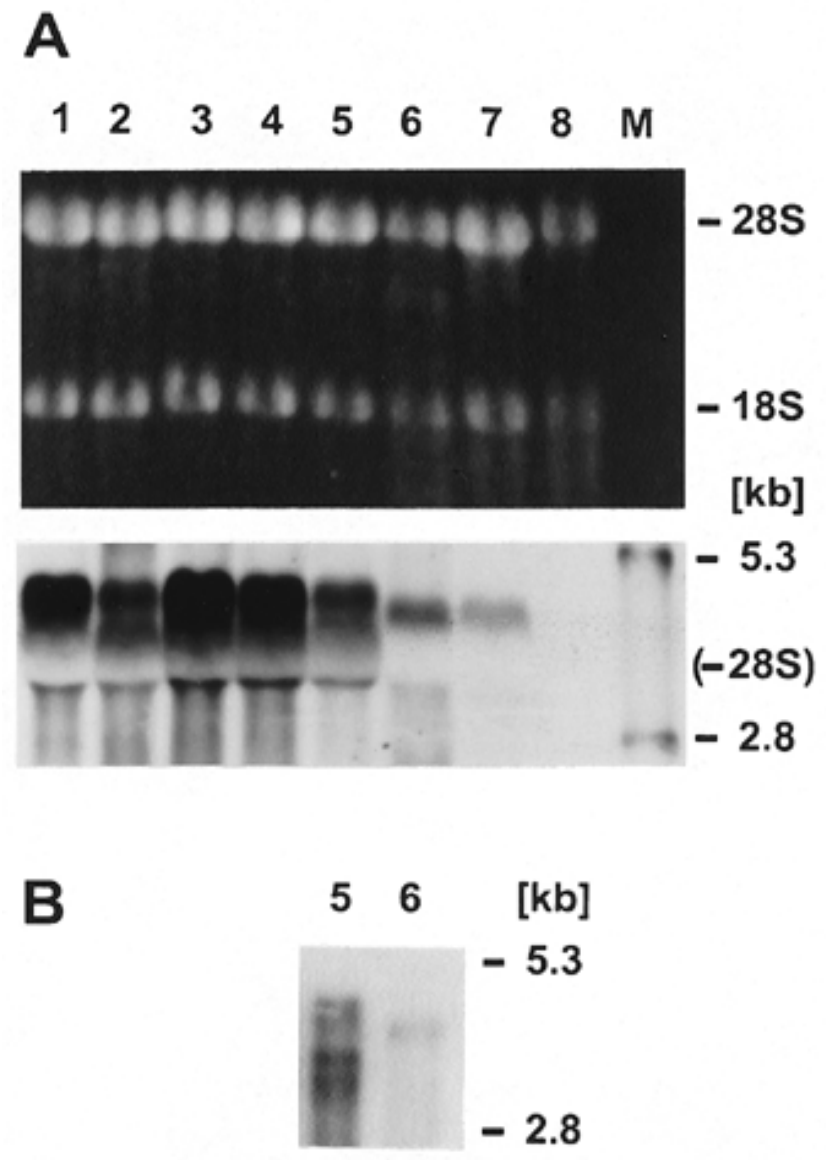

Fig. 4. Transcripts of Uf-PMA1 from Uromyces fabae during rust development, shown by Northern hybridization. A, Five micrograms of total RNA was loaded per lane, except for lane 7, on which ten micrograms was loaded (to compensate for the excess of plant RNA in the sample). The top portion is a photograph of the ethidium bromidestained agarose gel. The positions of the rRNAs are indicated. The bottom portion shows the hybridization result. The presence of the $28 \mathrm{~S}$ rRNA led to a displacement of the PMA1 mRNAs. Lane 1, uredospores; lane 2, 4-h-old germlings; lane 3, 6-h-old infection structures; lane 4, 12-h-old infection structures; lane 5, 18-h-old infection structures; lane 6, isolated haustoria; lane 7, infected Vicia faba leaves 5 days after inoculation with $U$. fabae; and lane 8, noninfected $V$. faba leaves. B, Two hundred nanograms of poly(A) RNA was loaded on each lane. cine. This indicated that both the rust wild-type $\mathrm{H}^{+}$-ATPase as well as the truncated enzyme could substitute functionally for the yeast enzyme.

To check whether the mutagenesis procedure leading to pUFPMA1 $\Delta 76$ had introduced further mutations, the complete coding region was amplified by PCR from DNA of yeast strain YAK2 (pUFPMA1 $\Delta 76$ ) and sequenced. In addition to the desired mutation, three further nucleotide substitutions were observed (discussed below). Two of them did not change the translation of the affected codons, whereas one led to a conservative amino acid exchange at position 695 (Val $\rightarrow$ Leu). Because this position is variable in $\mathrm{H}^{+}$-ATPases from other organisms, it is highly unlikely that the exchange has an effect on enzyme activity.

Western blot analysis with microsomal membranes confirmed that the rust $\mathrm{H}^{+}$-ATPases were expressed in the transformed yeast strain. Using antibodies specific against the Uromyces $\mathrm{H}^{+}$-ATPase, a membrane protein of $\approx 100 \mathrm{kDa}$, similar to the predicted molecular mass, was detected in YAK2 transformed with pUFPMA1 (Fig. 5). Compared to the wild-type, a smaller polypeptide was observed with YAK2 (pUFPMA1 $\Delta 76$ ) that expressed the deletion derivative of the Uromyces $\mathrm{H}^{+}$-ATPase. No cross-reaction of the antibodies was detected with strain YAK2 (cp(GAL1)PMA1). On the contrary, the yeast $\mathrm{H}^{+}$-ATPasespecific antiserum detected a polypeptide of $\approx 100 \mathrm{kDa}$ in YAK2 (cp(GAL1)PMA1) but not in the strains expressing rust $\mathrm{H}^{+}$-ATPase (Fig. 5).

\section{Enzymatic characterization of the rust $\mathrm{H}^{+}$-ATPases.}

Fractions of enriched plasma membranes of transformed yeast cells were used for the investigation of the enzymatic properties of the $\mathrm{H}^{+}$-ATPase. The P-type ATPases are highly sensitive to vanadate. For the rust wild-type PMA1, halfmaximal inhibition by vanadate was obtained at $30.1 \mu \mathrm{M}$. In contrast, the $\Delta 76$ deletion derivative displayed a threefold higher sensitivity (9.8 $\mu \mathrm{M}$; Fig. 6). When $\mathrm{pH}$ dependence was analyzed, a relatively broad $\mathrm{pH}$ optimum near 6.1 was found for Uf-PMA1, whereas the optimum of the $\Delta 76$ mutant was shifted to a more alkaline $\mathrm{pH}$ of 6.5 (Fig. 7). The kinetic properties of the enzymes are summarized in Figure 8. ATP hydrolysis measurements showed apparent $\mathrm{K}_{\mathrm{m}}$ values of $2.45 \mathrm{mM}$ (wild-type) and $0.82 \mathrm{mM}(\Delta 76)$, indicating a three-

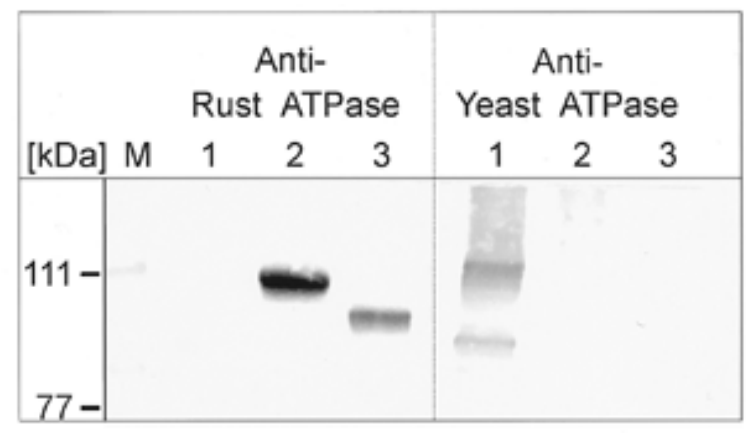

Fig. 5. Immunological detection of plasma membrane $\mathrm{H}^{+}$-ATPases expressed in yeast. Microsomal membrane proteins from yeast strains YAK2 (lane 1), YAK2 (pUFPMA1) (lane 2), and YAK2 (pUFPMA1 $\Delta 76$ ) (lane 3) were separated on a sodium dodecyl sulfate-polyacrylamide gel, transferred to polyvinylidene difluoride membranes and immunoprobed with anti-Uromyces PMA1 antibodies and antiyeast PMA1 serum, respectively. 
fold higher substrate affinity of the mutant enzyme. $V_{\max }$ was reduced in the $\Delta 76$ mutant $(2.85 \mu \mathrm{mol} \mathrm{Pi} / \mathrm{min} / \mathrm{mg})$ compared to the wild-type PMA1 ( $\left.V_{\max }=4.80 \mu \mathrm{mol} \mathrm{Pi} / \mathrm{min} / \mathrm{mg}\right)$. However, these results are based on the total amount of plasma membrane proteins applied in the enzyme assay. As indicated by the immunoblot analysis with microsomal membrane proteins (Fig. 5), as well as with enriched plasma membrane proteins (data not shown), the expression level in yeast of the $\Delta 76$ mutant seems to be lower than that of the wild-type.

\section{DISCUSSION}

In this paper, a molecular analysis of the rust PMAI gene and its functional expression in yeast is described. Although PMA genes have been isolated from fungi, algae, and plants, this is the first sequence from a plant pathogenic fungus and a basidiomycete. The deduced amino acid sequence of the rust enzyme is strikingly more similar to $\mathrm{H}^{+}$-ATPases from plants than from any other organisms, including ascomycetes. This is in contrast to the systematic relationships of the organisms, because basidiomycetes and ascomycetes are significantly more closely related to each other than the higher fungi are to plants. Other genes from $U$. fabae (e.g., Uf-TBBI encoding $\beta$ tubulin; S. Wirsel and M. Hahn, unpublished data) display lower similarity scores to their homologs in plants than to those in higher fungi, as expected based on taxonomic criteria. We have no plausible explanation for the paradoxical situation of $P M A 1$, although it is tempting to speculate that the close association and long period of coevolution of rust fungi and plants are responsible for the similarity of their $\mathrm{H}^{+}$-ATPases. We expect that the availability of more PMA sequences from other basidiomycetes will help solve this puzzle.

Genomic Southern hybridization indicated that $U f-P M A 1$ is present as a single-copy gene in the rust genome. This was

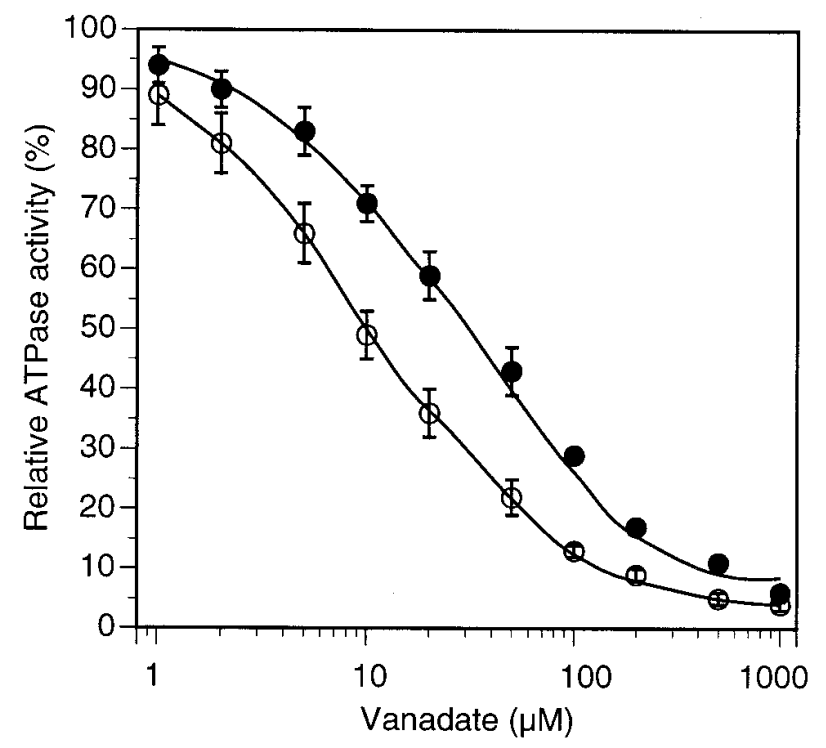

Fig. 6. Inhibition of plasma membrane $\mathrm{H}^{+}$-ATPases from Uromyces fab$a e$ by vanadate. Assays were performed in the presence of increasing concentrations of vanadate. The points are the means of five independent experiments, each with two measurements. Control activities without vanadate were $5.72 \mu \mathrm{mol} \mathrm{Pi} / \mathrm{min} / \mathrm{mg}$ for Uf-PMA1 (•) and 3.92 $\mu \mathrm{mol} \mathrm{Pi} / \mathrm{min} / \mathrm{mg}$ for Uf-PMA1 $\Delta 76(\mathrm{O})$. Apparent $K_{i}$ values for vanadate were $30.1 \mu \mathrm{M}$ for Uf-PMA1 and $9.8 \mu \mathrm{M}$ for Uf-PMA1 $\Delta 76$. supported by the observation that several independently isolated PMA cDNA clones from in vitro-grown infection structures and haustoria are identical (data not shown). In addition, the antibodies generated against peptides derived from the PMA1 sequence cross-reacted with a $100-\mathrm{kDa}$ membrane protein from $U$. fabae germ tubes (data not shown), confirming that the PMAl-encoded $\mathrm{H}^{+}$-ATPase is expressed. In $S$. cerevisiae and Schizosaccharomyces pombe, two PMA genes are present (de Kerchove d'Exaerde et al. 1996), whereas several copies exist in plants (e.g., at least 11 in Arabidopsis; De Witt et al. 1996).

Despite the evidence for a single genomic copy of $U f$-PMAl, a sequence dimorphism was observed in the coding region of $U f$-PMA1. This dimorphism is due to the presence of two nearly identical $P M A 1$ copies. A simple explanation for this may be the fact that rust fungi, as do most basidiomycetes, form dikaryotic mycelia during the main stages of their life cycle. The sequence dimorphism, therefore, could be due to differences in the two $U f$-PMAl alleles. Sequencing of RTPCR products revealed that both PMA1 copies are expressed to a similar extent in in vitro-grown infection structures and haustoria. This suggests, that both nuclei contribute equally to the expression of PMA1 throughout rust development.

Northern blot hybridizations indicate that $U f-P M A l$ is under transcriptional control; whereas several transcripts were observed during early in vitro development, only a single PMAI transcript of different size and lower abundance was found in haustoria and rust-infected leaves. In fungi, multiple transcripts originating from single genes have been observed in several cases; they can be due to alternative transcriptional start sites (Wu and Tzagoloff 1987) or different 3' termini (Girard et al. 1993). The apparent change in the transcript pattern of Uf-PMAl is similar in its timing to the increased expression of a number of in planta-induced genes from $U$. fabae (Hahn and Mendgen 1997). A different regulation was found in the facultative pathogenic fungus Candida albicans,

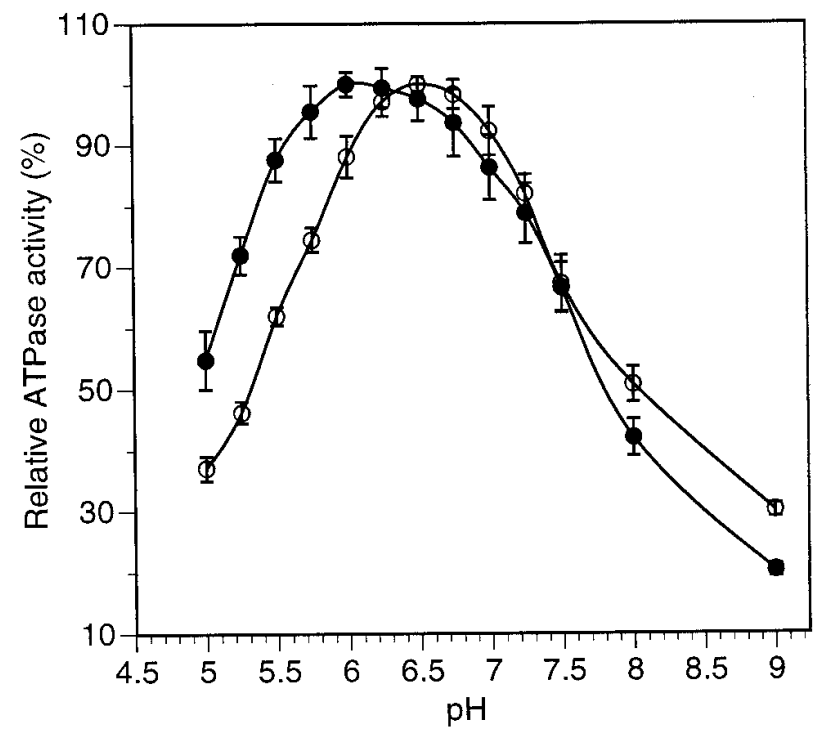

Fig. 7. Effect of $\mathrm{pH}$ on $\mathrm{H}^{+}$-ATPase from Uromyces fabae activity. The points are the means of four independent experiments, each with two measurements. The optimum activities $(100 \%)$ of Uf-PMA1 (•) and UfPMA1 $\Delta 76$ (O) were 4.78 and $2.89 \mathrm{Pi} / \mathrm{min} / \mathrm{mg}$, respectively. 
in which PMA1 expression in starved cells increased severalfold during glucose-induced yeast growth and, to a lesser extent, during germ tube formation (Monk et al. 1993).

The increased activity of the $\mathrm{H}^{+}$-ATPase in rust haustoria compared to spores and germlings (Struck et al. 1996) is not

$\mathbf{A}$

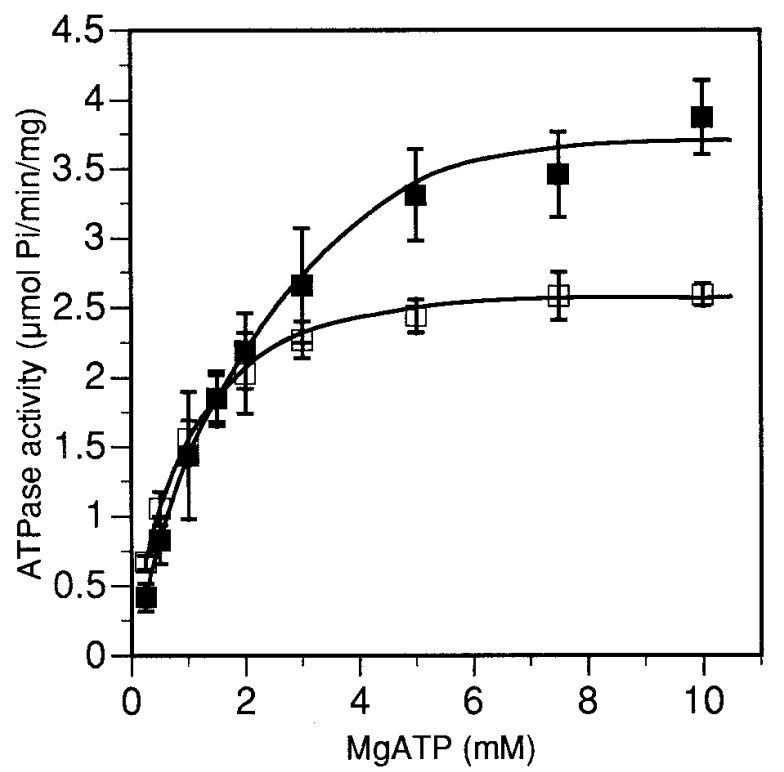

B

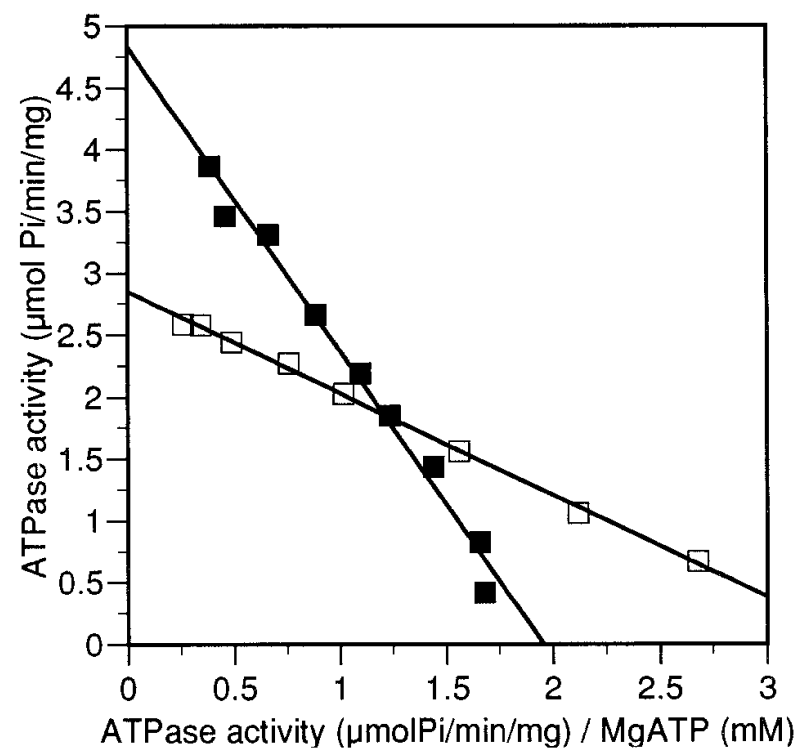

Fig. 8. Kinetic properties of the rust (Uromyces fabae) wild-type (ם) and $\Delta 76(\square) \mathrm{H}^{+}$-ATPases. A, Effect of ATP concentration on $\mathrm{H}^{+}$-ATPase activity. The enzyme reaction mixture contained the indicated concentration of $\mathrm{MgATP}$, with $1 \mathrm{mM}$ free $\mathrm{Mg}^{2+}$. The points are the means of three independent experiments, each with one or two measurements. B, Eadie-Hofstee plots of the data shown in A. The slope of the curves gives $-K_{m}$. The apparent $K_{m}$ for Uf-PMA1 $=2.44 \mathrm{mM}$ and for UfPMA1 $\Delta 76=0.82 \mathrm{mM}$. The intercepts with the ordinate give $V_{\max }$ for $U f$ PMA1 $=4.80 \mu \mathrm{mol} \mathrm{Pi} / \mathrm{min} / \mathrm{mg}$ and for Uf-PMA1 $\Delta 76=2.85 \mu \mathrm{mol} \mathrm{Pi} /$ $\mathrm{min} / \mathrm{mg}$. due to higher PMAl transcript levels. Therefore, posttranscriptional regulation of PMAI expression can be postulated. With at least $386 \mathrm{nt}$, the $5^{\prime}$ untranslated leader of the $U f-P M A 1$ mRNA is unusually long and contains an intron and a short upstream ORF. Long 5' leader sequences (>200 nt) containing short ORFs also have been observed in yeast PMAl (Capieaux et al. 1989) and several plant PMA genes (Perez et al. 1992). A role of the $5^{\prime}$ leader sequence in translational regulation has been demonstrated for the pmal gene of Nicotiana plumbaginifolia (Michelet et al. 1994). Based on these structural similarities, the $U f$-PMAl leader sequence also may play a regulatory role.

Expression of plant and fungal $\mathrm{H}^{+}$-ATPases in yeast is a powerful tool that allows detailed characterization of their enzymatic properties. However, in most cases, full complementation of yeast mutants defective in their own ATPases has not been possible, in part due to mistargeting of the enzymes in microsomal membranes (Villalba et al. 1992; Palmgren and Christensen 1994; de Kerchove d'Exaerde et al. 1997). In light of the relatively low degree of homology between rust and yeast enzymes, it is somewhat surprising that the rust $\mathrm{H}^{+}$ATPase can fully complement a yeast mutant lacking PMAl and PMA2. Nevertheless, a high proportion of the rust enzyme was found in the microsomal membrane fraction (data not shown), indicating that the mechanism leading to translocation of the newly synthesized Uf-PMA1 into the plasma membrane is saturated (de Kerchove d'Exaerde et al. 1996).

A derivative of the rust $\mathrm{H}^{+}$-ATPase that lacks 76 amino acids of the hydrophilic $\mathrm{C}$ terminus also was able to support growth of the yeast mutant, although the transformants grew more slowly than those complemented with the wild-type $U f$ PMA1 (data not shown). Comparison of the enzymatic properties revealed a higher substrate affinity, a higher sensitivity to vanadate, and a more alkaline $\mathrm{pH}$ optimum of the $\Delta 76$ mutant. These attributes are similar to those of the activated forms of plant and yeast $\mathrm{H}^{+}$-ATPases obtained either in the presence of activators, such as glucose (for yeast) and fusicoccin (for plants), or by removal of the C-terminal region (Regenberg et al. 1995). Thus, similar to the enzymes of yeast and plants, the long hydrophilic C-terminus of the rust $\mathrm{H}^{+}$ATPase is nonessential for its activity and appears to have an autoregulatory effect. The reduction of the calculated $V_{\max }$ of the $\Delta 76$ mutant, appears to be due to a lower level of expression than the wild-type enzyme in yeast.

Based on data presented previously (Struck et al. 1996; Hahn et al. 1997) and in this work, we suggest that the plasma membrane $\mathrm{H}^{+}$-ATPase plays an essential role in parasitic growth of the rust fungus, and its expression is regulated at several levels, leading to increased enzyme activities in haustoria to provide sufficient capacity for active nutrient transport. Nevertheless, we still know very little about the mechanisms behind this regulation. In contrast to the yeast PMA1 ATPase, we could not detect an effect of glucose on the activity of the enzyme, neither in germinated rust spores nor in transformed yeast cells (C. Struck, unpublished data). In rust fungi, morphogenetic differentiation and gene expression appear to be part of a developmental program that governs the series of events occurring during infection (Mendgen et al. 1996; Hahn and Mendgen 1997). It sems that the expression of the plasma membrane $\mathrm{H}^{+}$-ATPase is largely controlled by this program. 


\section{MATERIALS AND METHODS}

\section{Organisms and media.}

The rust fungus $U$. fabae race $\mathrm{I}_{2}$ was propagated on its host plant, Vicia faba cv. Con Amore, as described previously (Deising et al. 1991). Germinated spores, infection structures, and haustoria used for RNA isolation were obtained as described previously (Hahn and Mendgen 1997).

S. cerevisiae strain YAK2 (provided by M. Boutry, Louvainla-Neuve, Belgium) (de Kerchove d'Exaerde et al. 1995) (MAT $\alpha$, ade2-101, leu2 $\Delta 1$, his3- $\Delta 200$, ura3-52, trp1 $\Delta 63$, lys2801 , pma1 $\Delta::$ HIS3, pma2- $\Delta::$ TRP1) carrying the plasmid cp(GAL1)PMA1 (p(GAL1)::PMA1, CEN6, ARSH4, URA3) was used for heterologous expression of U. fabae PMAl. Cells were grown in synthetic medium containing either $2 \%$ galactose or $2 \%$ glucose, $0.67 \%$ yeast nitrogen base without amino acids (Difco, Detroit, MI), and 0.2\% amino acid dropout mix (Rose et al. 1990) without leucine and uracil, which were used for selection (each at $20 \mathrm{mg} / \mathrm{liter}$ ). The medium containing 5-fluoroorotic acid (Sigma, St. Louis, MO) was prepared as described previously (Boeke et al. 1984).

\section{DNA and RNA manipulations.}

The degenerate oligonucleotide [5'-CGTTCATGACIGGIGA(T/C)GGIGTIAA(T/C)GA(T/C)GC-3'], corresponding to the amino acid sequence MTGDGVNDA conserved in $\mathrm{H}^{+}$ATPases, was coupled at its $3^{\prime}$ terminus with alkaline phosphatase according to Jablonski et al. (1986), using the LightSmith II protocol (Promega, Madison, WI).

For the isolation of a full-length PMAI cDNA clone from a haustorium-specific $U$. fabae $\lambda$ gt10 cDNA library (Hahn and Mendgen 1997), a 639-bp DIG-labeled PCR fragment was obtained from a genomic PMAl clone with primers P1 (AACAATATCACCAGGGACGAGG) and MW1 (CACTCGTCGACATTGGAACCA) and used.

DNA and RNA blot hybridizations with DIG-labeled probes were done as described previously (Hahn and Mendgen 1997). PCR, plasmid isolation, and subcloning in Escherichia coli were performed according to standard protocols (Sambrook et al. 1989).

For expression of $U f-P M A 1 \mathrm{cDNA}$ in yeast, the expression vector YEpXNB was constructed by inserting the $P M A 1$ promotor/ADH1 terminator cassette from the vector pDR195 (Rentsch et al. 1995) as a 1.1-kb SphI (blunted by Klenow DNA polymerase)/HindIII fragment into the corresponding sites (SacI [blunted]/HindIII) of YEplac181 (Gietz and Sugino 1988). A 3.5-kb BamHI/NotI fragment (blunted) obtained from $\lambda$ gt10-UFPMA1 was inserted into the NotI site of YEpXNB (blunted) in the appropriate orientation, resulting in plasmid YEp(PMA1)UFPMA1. Yeast strain YAK2 (de Kerchove d'Exaerde et al. 1995) was transformed according to Ausubel et al. (1992).

DNA sequencing was performed with fluorescently or DIGlabeled dideoxynucleotide chain terminators and an ABI 373 automatic sequencer (Perkin Elmer, Foster City, CA) or GATC 1500 direct blotting electrophoresis system (Pohl and Maier 1995).

\section{Mutagenesis.}

Site-directed mutagenesis was performed with plasmid YEp(PMA1)UFPMA1. Using the QuikChange site-directed mutagenesis procedure (Stratagene, La Jolla, CA), codon 887 was changed from AAG to TAG at position 3044 of the PMAI cDNA, resulting in plasmid YEp(PMA1)UFPMA1- $\Delta 76$. Sequence analysis revealed that the mutagenesis procedure resulted in three additional nucleotide exchanges being introduced into the PMA1- $\triangle 76$ coding region at positions $1789(\mathrm{G} \rightarrow$ $\left.\mathrm{T} ; \mathrm{L}_{468}\right), 2468\left(\mathrm{G} \rightarrow \mathrm{T} ; \mathrm{V}_{695} \rightarrow \mathrm{I}_{695}\right)$, and $2680\left(\mathrm{~T} \rightarrow \mathrm{A} ; \mathrm{L}_{765}\right.$; discussed above).

\section{Antisera.}

Polyclonal antibodies were raised against a mixture of two synthetic peptides (coupled to keyhole limpet hemocyanin; Baldwin 1994) specific for Uf-PMA1 (AS 480 to 489: TESGQMRRVT; AS 610 to 621: KDGPEPGGKFSSLDE) and affinity-purified with a peptide-Sepharose 4B column (Pagano 1996). The polyclonal antiserum against the $S$. cerevisiae $\mathrm{H}^{+}$-ATPase (number 838 ) was provided by R. Serrano, Valencia, Spain.

\section{Immunoblot analysis.}

Membrane proteins (10 $\mu \mathrm{g}$ of microsomal fraction) were separated by sodium dodecyl sulfate-gel electrophoresis on a $9.5 \%$ polyacrylamide gel (Schägger and von Jagow 1987) and electroblotted to a polyvinylidene fluoride membrane (KyhseAndersen 1984). Immunological detection was done according to Blake et al. (1984), with $U$. fabae antipeptide antibodies $(1: 200)$ or yeast antiserum $(1: 10,000)$ and horseradish peroxidase-conjugated anti-rabbit immunoglobulin $\mathrm{G}$ as secondary antibodies.

\section{Isolation of plasma membranes.}

For plasma membrane isolation, 800-ml overnight cultures of the transformed yeast strains were harvested in late exponential phase, washed in ice-cold water, and incubated in $250 \mathrm{mM}$ galactose for $15 \mathrm{~min}$. Plasma membranes were purified by differential and sucrose gradient centrifugation (Serrano 1988). Microsomal membranes were layered on top of $8 \mathrm{ml}$ each of 50 and $42 \%$ (wt/wt) sucrose and centrifuged for $4 \mathrm{~h}$ at 35,000 rpm in a Ti60 rotor (Beckman Instruments $\mathrm{GmbH}$, Palo Alto, CA). The collected plasma membrane fraction was pelleted by centrifugation for $40 \mathrm{~min}$ at $80,000 \times g$. The protein concentration was determined by the method of Bradford (1976), using the Bio-Rad microassay (Bio-Rad Laboratories, Hercules, CA) adapted for microtiter plates.

\section{$\mathrm{H}^{+}$-ATPase assay.}

The rate of ATP hydrolysis was measured colorimetrically (Ames 1966). Standard measurements were performed at $30^{\circ} \mathrm{C}$ and pH 6.5 in a solution described by Struck et al. (1996). For determination of kinetic parameters and $\mathrm{pH}$ profiles, the amounts of ATP and $\mathrm{Mg}^{2+}$ added were calculated to obtain $5 \mathrm{mM} \mathrm{Mg}$ ATP (or as indicated) and $1 \mathrm{mM}$ free $\mathrm{Mg}^{2+}$, using the equations described by Wach et al. (1990).

\section{ACKNOWLEDGMENTS}

This work was done in the laboratory of K. Mendgen to whom we are indebted for his continuous support and advice in this project. We also thank M. Boutry (Louvain-la-Neuve) for providing us with the strain YAK2; R. Serrano (Valencia) for the gift of anti-yeast ATPase antibodies; H. Hennecke and K. Apel (Zurich) for providing their sequence facilities; and S. Wirsel for helpful comments on the manuscript. This 
work was supported by the Deutsche Forschungsgemeinschaft (grants Me-523/14, Me-523/18, and Ha-486/2).

\section{LITERATURE CITED}

Ames, B. N. 1966. Assay of inorganic phosphate, total phosphate and phosphatase. Methods Enzymol. 8:115-118.

Ausubel, F. M., Brent, R., Kingston, R. E., Moore, D. D., Seidman, J. G., Smith, J. A., and Struhl, K. 1992. Short protocols in molecular biology. John Wiley \& Sons, New York.

Baka, Z. A., Larous, L., and Lösel, D. M. 1995. Distribution of ATPase activity at the host-pathogen interfaces of rust infections. Physiol. Mol. Plant Pathol. 47:67-82.

Baldwin, S. A. 1994. Use of antipeptide antibodies for the isolation and study of membrane proteins. Methods Mol. Biol. 27:43-63.

Blake, M. S., Johnston, K. H., Russell-Jones, G. J., and Gotschlich, E. C. 1984. A rapid, sensitive method for detection of alkaline phosphataseconjugated anti-antibody on Western blots. Anal. Biochem. 136:175179.

Boeke, J. D., LaCroute, F., and Fink, G. R. 1984. A positive selection for mutants lacking orotidine- $5^{\prime}$-phosphate decarboxylase activity in yeast: 5-Fluoro-orotic acid resistance. Mol. Gen. Genet. 197:345-346.

Bradford, M. M. 1976. A rapid and sensitive method for the quantitation of microgram quantities of protein utilizing the principle of proteindye binding. Anal. Biochem. 72:248-254.

Capieaux, E., Vignais, M.-L., Sentenac, A., and Goffeau, A. 1989. The yeast $\mathrm{H}^{+}$-ATPase gene is controlled by the promoter binding factor TUF. J. Biol. Chem. 264:7437-7446.

Deising, H., Jungblut, P. R., and Mendgen, K. 1991. Differentiation-related proteins of the broad bean rust fungus Uromyces viciae-fabae, as revealed by high resolution two-dimensional polyacrylamide gel electrophoresis. Arch. Microbiol. 155:191-198.

de Kerchove d'Exaerde, A. D., Morsomme, P., Sempoux-Thinès, D. Supply, P., Goffeau, A., and Ghislain, M. 1997. Functional analysis of chimerical plasma membrane $\mathrm{H}^{+}$-ATPases from Saccharomyces cerevisiae and Schizosaccharomyces pombe. Mol. Microbiol. 25:261-273.

de Kerchove d'Exaerde, A. D., Supply, P., Dufour, J. P., Bogaerts, P., Thines, D., Goffeau, A., and Boutry, M. 1995. Functional complementation of a null mutation of the yeast Saccharomyces cerevisiae plasma membrane $\mathrm{H}^{+}$-ATPase by a plant $\mathrm{H}^{+}$-ATPase gene. J. Biol. Chem. 270:23828-23837.

de Kerchove d'Exaerde, A. D., Supply, P., and Goffeau, A. 1996. Subcellular traffic of the plasma membrane $\mathrm{H}^{+}$-ATPase in Saccharomyces cerevisiae. Yeast 12:907-916.

De Witt, N. D., Hong, B. M., Sussman, M. R., and Harper, J. F. 1996. Targeting of two Arabidopsis $\mathrm{H}^{+}$-ATPase isoforms to the plasma membrane. Plant Physiol. 112:833-844.

Eraso, P., and Portillo, F. 1994. Molecular mechanism of regulation of yeast plasma membrane $\mathrm{H}^{+}$-ATPase by glucose-Interaction between domains and identification of new regulatory sites. J. Biol. Chem. 269:10393-10399.

Gietz, D. R., and Sugino, A. 1988. New yeast-Escherichia coli shuttle vectors constructed with in vitro mutagenized yeast genes lacking sixbase pair restriction sites. Gene 74:527-534.

Girard, J. P., Feliu, J., Caizergues-Ferrer, M., and Lapeyre, B. 1993. Study of multiple fibrillarin mRNAs reveals that $3^{\prime}$ end formation in Schizosaccharomyces pombe is sensitive to cold shock. Nucleic Acids Res. 21:1881-1887.

Hahn, M., and Mendgen, K. 1997. Characterization of in planta-induced rust genes isolated from a haustorium-specific cDNA library. Mol. Plant-Microbe Interact. 10:427-437.

Hahn, M., Neef, U., Struck, C., Göttfert, M., and Mendgen, K. 1997. A putative amino acid transporter is specifically expressed in haustoria of the rust fungus Uromyces fabae. Mol. Plant-Microbe Interact. 10: 438-445.

Higgins, D G., and Sharp, P. M. 1989. Fast and sensitive multiple sequence alignments on a microcomputer. Comput. Appl. Biosci. 5:151153.

Hofmann, K., and Stoffel, W. 1993. TMbase-A database of membrane spanning proteins segments. Biol. Chem. Hoppe-Seyler 347:166.

Jablonski, E., Moomaw, E. W., Tullis, R. H., and Ruth, J. L. 1986. Preparation of oligodeoxynucleotide-alkaline phosphatase conjugates and their use as hybridization probes. Nucleic Acids Res. 15:6115-6128.
Johansson, F., Sommarin, M., and Larsson, C. 1993. Fusicoccin activates the plasma membrane $\mathrm{H}^{+}$-ATPase by a mechanism involving the C-terminal inhibitory domain. Plant Cell 5:321-327.

Kyhse-Andersen, J. 1984. Electroblotting of multiple gels: A simple apparatus without tank for rapid transfer of proteins from polyacrylamide to nitrocellulose. J. Biochem. Biophys. Methods 10: 203-209.

Mendgen, K., Hahn, M., and Deising, H. 1996. Morphogenesis and mechanisms of penetration by plant pathogenic fungi. Annu. Rev. Phytopathol. 34:367-386.

Michelet, B., Lukaszewicz, M., Dupriez, V., and Boutry, M. 1994. A plant plasma membrane proton-ATPase gene is regulated by development and environment and shows signs of a translational regulation. Plant Cell 6:1375-1389.

Monk, B. C., Niimi, M., and Shepherd, M. G. 1993. The Candida albicans plasma membrane and $\mathrm{H}^{+}$-ATPase during yeast growth and germ tube formation. J. Bacteriol. 175:5566-5574.

Pagano, M. 1996. From peptide to purified antibody. Pages 271-280 in: Cell Cycle-Materials and Methods. M. Pagano, ed. Springer, Berlin.

Palmgren, M. G., and Christensen, G. 1994. Functional comparisons between plant plasma membrane $\mathrm{H}^{+}$-ATPase isoforms expressed in yeast. J. Biol. Chem. 269:3027-3033.

Palmgren, M. G., Sommarin, M., Serrano, R., and Larsson, C. 1991. Identification of an autoinhibitory domain in the C-terminal region of the plant plasma membrane $\mathrm{H}^{+}$-ATPase. J. Biol. Chem. 266:2047020475.

Perez, C., Michelet, B., Ferrant, B., Bogaerts, P., and Boutry, M. 1992. Differential expression within a three-gene subfamily encoding a plasma membrane $\mathrm{H}^{+}$-ATPase in Nicotiana plumbaginifolia. J. Biol. Chem. 267:1204-1211.

Pohl, T., and Maier, E. 1995. Sequencing $500 \mathrm{~kb}$ of yeast DNA using a GATC 1500 direct blotting electrophoresis system. BioTechniques 19: 482-486.

Portillo, F., Eraso, P., and Serrano, R. 1991. Analysis of the regulatory domain of yeast plasma membrane $\mathrm{H}^{+}$-ATPase by directed mutagenesis and intragenetic suppression. FEBS Lett. 287:71-74.

Regenberg, B., Villalba, J. M., Lanfermeijer, F. C., and Palmgren, M. G. 1995. C-terminal deletion analysis of plant plasma membrane $\mathrm{H}^{+}$. ATPase: Yeast as a model system for solute transport across the plant plasma membrane. Plant Cell 7:1655-1666.

Rentsch, D., Laloi, M., Rouhara, I., Schmelzer, E., Delrot, S., and Frommer, W. B. 1995. NTR1 encodes a high affinity oligopeptide transporter in Arabidopsis. FEBS Lett. 370:264-268.

Rose, M. D., Winston, F., and Hieter, P. 1990. Methods in Yeast Genetics: A Laboratory Course Manual. Cold Spring Harbor Laboratory, Cold Spring Harbor, NY.

Sambrook, J., Fritsch, E. F., and Maniatis, T. 1989. Molecular Cloning: A Laboratory Manual. Cold Spring Harbor Laboratory, Cold Spring Harbor, NY.

Schägger, H., and von Jagow, G. 1987. Tricine-sodium dodecyl sulfatepolyacrylamide gel electrophoresis for the separation of proteins in the range from 1 to $100 \mathrm{kDa}$. Anal. Biochem. 166:368-379.

Serrano, R. 1988. H'-ATPase from plasma membrane of Saccharomyces cerevisiae and Avena sativa roots: Purification and reconstitution. Methods Enzymol. 157:533-544.

Serrano, R. 1989. Structure and function of plasma membrane $\mathrm{H}^{+}$ ATPase. Annu. Rev. Plant Physiol. Plant Mol. Biol. 40:61-94.

Spencer-Phillips, P. T. N., and Gay, J. L. 1981. Domains of ATPase in plasma membranes and transport through infected plant cells. New Phytol. 89:393-400.

Struck, C., Hahn, M., and Mendgen, K. 1996. Plasma membrane $\mathrm{H}^{+}$ATPase activity in spores, germ tubes, and haustoria of the rust fungus Uromyces viciae-fabae. Fungal Genet. Biol. 20:30-35.

Villalba, J. M., Palmgren, M. G., Berberian, G. E., Ferguson, C., and Serrano, R. 1992. Functional expression of plant plasma membrane $\mathrm{H}^{+}$-ATPase in yeast endoplasmic reticulum. J. Biol. Chem. 267:1234112349.

Wach, A., Ahlers, J., and Gräber, P. 1990. The $\mathrm{H}^{+}$-ATPase of the plasma membrane from yeast. Kinetics of ATP-hydrolysis in native membranes, isolated and reconstituted enzymes. Eur. J. Biochem. 189:675682

Wu, M., and Tzagoloff, A. 1987. Mitochondrial and cytoplasmic fumarases in Saccharomyces cerevisiae are encoded by a single nuclear gene FUM1. J. Biol. Chem. 262:12275-12282. 